Copyright (C) 2021 by Cherkas Global University

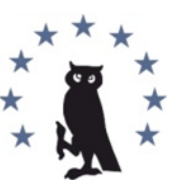

Published in the USA

European Journal of Physical Education and Sport

Has been issued since 2013.

E-ISSN: 2409-1952

2021. $9(1): 25-31$

DOI: 10.13187/ejpe.2021.1.25

https://ejpes.cherkasgu.press

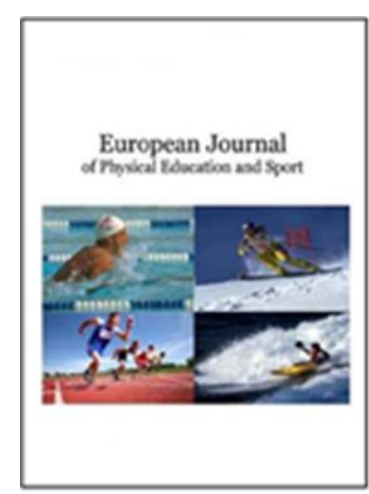

\title{
Basketball Reserve Preparation: Problems and Prospects
}

\author{
Victor Koryahin a, Oksana Blavt ${ }^{a}$, *, Tatyana Gurtova a \\ a Lviv Polytechnic National University, Ukraine
}

\begin{abstract}
The article considers the main aspects of the formation of sportsmanship of young basketball players. It is established that the program of long-term training of basketball players is focused on the demonstration of physical and technical training of basketball players, which is considered as a leading strategic direction of training young highly qualified athletes in modern conditions. The paper presents the results of research on the level of physical and technical fitness of young basketball players. According to the results of empirical research it is established that insufficient development of all physical qualities increases the duration of formation of special skills during mastering the technique of basketball and reduces the efficiency of their use in competitive wrestling. It was found that the training of young basketball players should be aimed at realizing the maximum opportunities for each athlete in the optimal period for the demonstration of sports results. The presented results can be used as a scientific basis for a purposeful choice of means and methods of training to improve the structure of comprehensive training of young basketball players.
\end{abstract}

Keywords: sports training, young basketball, physical fitness, qualities.

\section{Introduction}

The progress of high-achievement sports is associated with the substantiation of elements of the system of athletes and its focus on sports results (Csataljay et al., 2009; Köklü et al., 2011). Training high-class basketball players is a complex, dynamic pedagogical process based on a deep understanding of the causes of the factors that determine its effectiveness under the direct influence of the changes taking place in basketball (Erculj et al., 2009; Köklü et al., 2011). This requires mastering a set of knowledge of the latest scientific advances in the training of highly qualified athletes.

The system of sports training of basketball players should reflect in full and take into consideration the actions that a sportsman performs in the course of the competition (Doroshenko et al., 2019; Koryahin et al., 2016). Modern basketball requires from sportsmen high functional training and perfect mastering of all techniques of the game (Tsamourtzis et al., 2002). It has been proved (Koryahin et al., 2016; Savoy et al., 1997) that physical training and its organic interconnection with technical training is of great importance for the growth of basketball players' skills. Technical training determines the effectiveness of the training process (Cañadas et al., 2015; Villani et al., 2017). The scientific substantiation of this interconnection enables to effectively prepare basketball players of high class in the course of many years of training.

\footnotetext{
${ }^{*}$ Corresponding author

E-mail addresses: oksanablavt@ukr.net (O. Blavt), koryahinv@meta.ua (V. Koryahin), hurtova@i.ua (T. Gurtova)
} 


\section{Methods}

Participants. Basketball players of all ages and qualifications were involved in the study, and namely: young basketball players aged 11 to 17 years old in the following quantity: 11 years old 105, 12 years old $-101,13$ years old $-115,14$ years old $-101,15$ years old $-102,16$ years old -101 , 17 years old -109 and skilled basketball players aged 18-19 years -17 persons, 20 years old and older - 74 basketball players who were of masters of sports and honoured masters of sports. The study was conducted in compliance with the World Medicine Association declaration of Helsinki: Ethical principles for medical research involving human subjects, 2013.

Procedures. In order to conduct the study, tests were used to assess the technical and physical fitness of the basketball players (Mancha-Triguero et al., 2019).

In order to assess the technical fitness, the following was used: movement in a defensive stance, push-passing the ball in a give-and-go play with two hands and an over-arm pass with one hand within 30 seconds at a distance of $2 \mathrm{~m}$ from the wall, foul shots, jump shots, a complex exercise in running, passing, catching, driving and throwing the ball into the basket, running for $20 \mathrm{~m}$, standing long jump, height of jumping up with pushing of two legs, 3x40 sec running on the basketball court after 1 minute of rest. All tests meet the basic criteria of the theory of tests.

The assessment of the physical development of the basketball players was carried out using the anthropometry method for measuring the size and mass. The hand strength was determined by the method of dynamometry. Spirometry was used to determine external respiration.

Statistical analysis. All statistical analyses were performed using SPSS Version 21. For each characteristic there were determined average values, standard deviations, and Student criterion for unrelated samples.

\section{Discussion}

Based on the analysis of studying this issue (Ben Abdelkrim et al., 2010; Köklü et al., 2011; Kuczek et al., 2013), it has been established that the rapid development of achievements in world sports requires continuous search for new and more effective means of technical and physical training of basketball players. The assessment and analysis of the system of training and the results of the performances of the world's strongest sportsmen (Ben Abdelkrim et al., 2010; Kuczek et al., 2013; Villani et al., 2017) show, that success can only be achieved as a result of many years of training. It has been found out (Mulazimoglu et al., 2017), that it is precisely in adolescence that the formation of the foundation for further development and improvement of physical qualities takes place, on which the formation of basketball players' skills will depend in the future (Cañadas et al., 2015). That is why it is necessary to help remove disadvantages in the level of physical development and physical fitness of young sportsmen already at the early stages of many-years training.

The topicality of the study is stipulated by the need for an analysis of the existing system of physical and technical training of young basketball players, which makes it possible to purposefully select means and methods of training to improve the structure of complex training on a scientific basis.

\section{Results}

The study of the growth indicators of young basketball players in Ukraine showed that the height at the age of 12 and 13 years may be classified as a good level, and the height at the age of $15-17$ years old is "below average" and is: at the age of 15 years old $-181.9 \mathrm{~cm}$, at the age of 16 years old $-187.6 \mathrm{~cm}$ and at the age of 17 years old $-190.6 \mathrm{~cm}$. The growth rates of young players at the age 18-19 years old (196.4 and $199 \mathrm{~cm}$ respectively) may be classified as optimal rate.

It has been found out that the growth indicator of young basketball players standing on tiptoe with a stretched up hand increases with age from $189.1 \mathrm{~cm}$ to $267.1 \mathrm{~cm}$ at the age of 19 years old and up to $269.2 \mathrm{~cm}$ in basketball players who are honoured masters of sports and masters of sports of international class. The dynamics of this indicator and growth rate are shown in Figures 1, 2. The obtained results make it possible to state that, until the age of 17-18 years old, basketball players generally reach the limit values of these indicators. It has been found out that the dynamics of these indicators has linear dependence up to the age of 17-18 years old. 


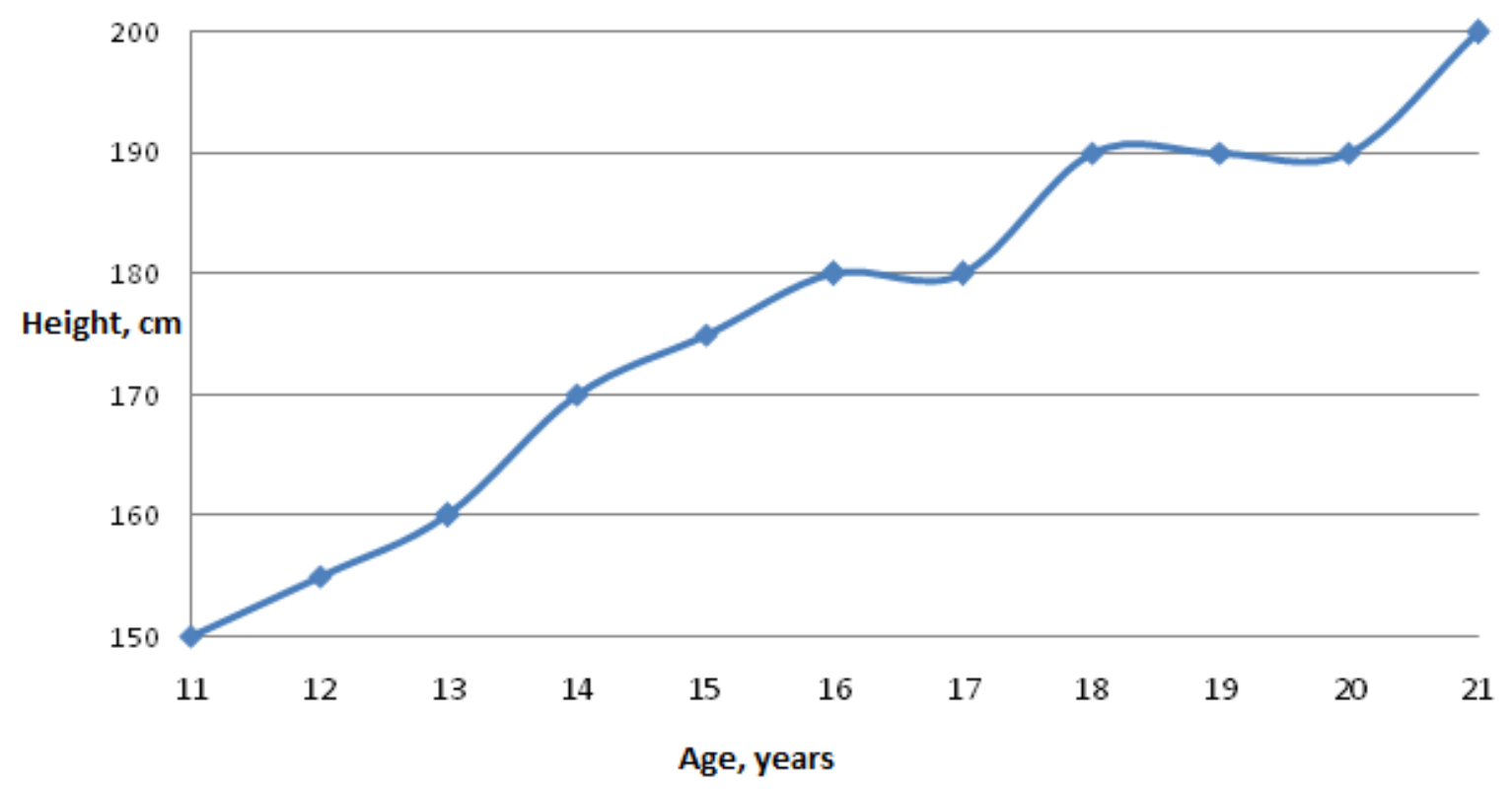

Fig. 1. Dynamics of growth rates of young basketball players

Results in the tests that characterize the speed-strength fitness of sportsmen show that in general, young basketball players in Ukraine have low indicators in the height of jumping up (Figures 3 and 4).

The young basketball players' low indicators in the relative height of jumping up, as well as other speed-strength indicators have been received. The following results have been obtained by testing the relative height of the in basketball players' jump: 11 years old players $-32.17 \mathrm{~cm}$, 12 years old players $-36.8 \mathrm{~cm}, 13$ years old players $-42.00 \mathrm{~cm}, 14$ years old players $-43.10 \mathrm{~cm}$, 15 years old players $-46.90 \mathrm{~cm}, 16$ years old players $-48.40 \mathrm{~cm}, 17$ years old players $-49.90 \mathrm{~cm}$, 18 years old players $-54.00 \mathrm{~cm}, 19$ years old players $-55.00 \mathrm{~cm}$. A similar picture is observed in the indicators of 6 and $20 \mathrm{~m}$ running and a standing upward jump off both feet.

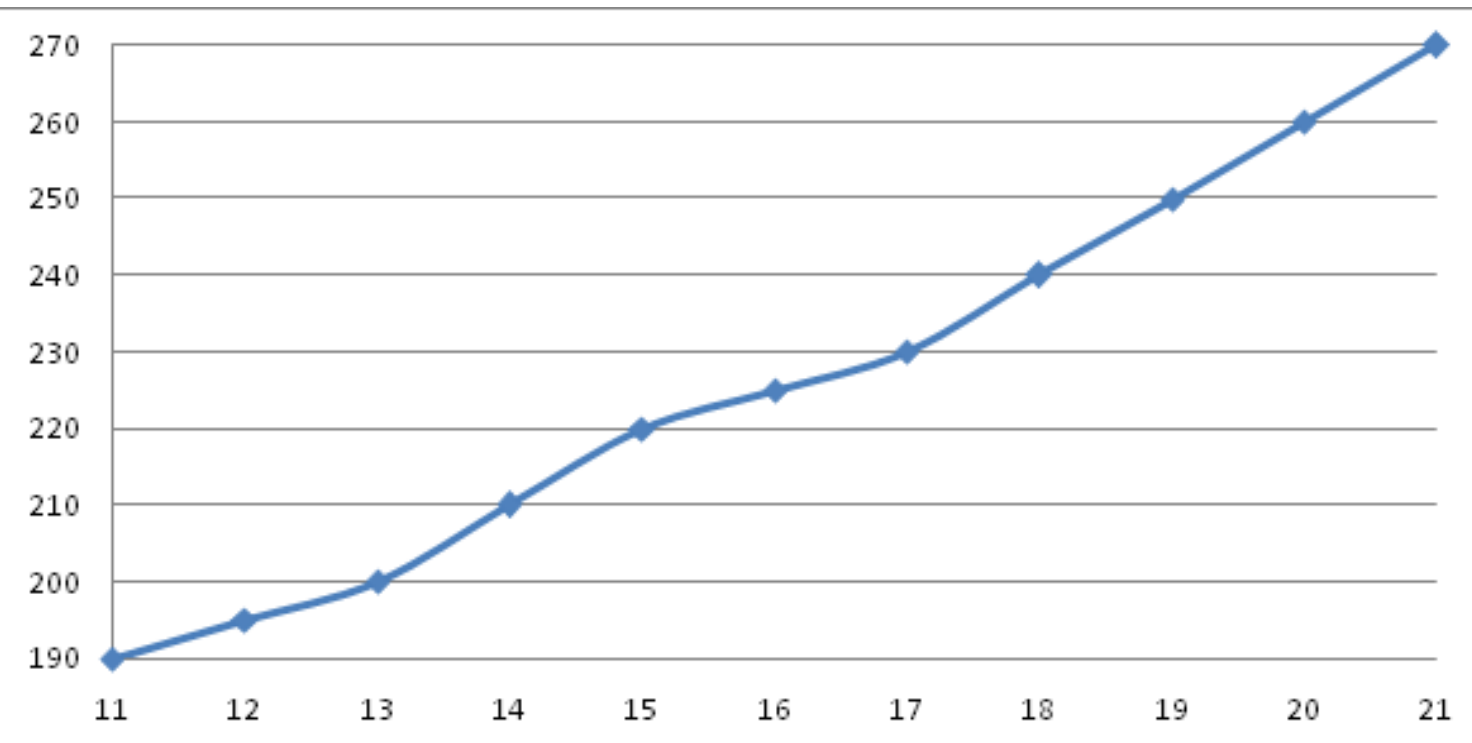

On toe, cm

Age, years

Fig. 2 Dynamics of growth rates on tiptoe with a stretched hand up 
The results of the study revealed that the level of development of high-speed endurance is gradually increasing from year to year up to 17 years. 18 and 19 years old basketball players of high qualification (masters of sports) have much higher high-speed endurance. This is evidenced by the results shown in Figure 5.

The studies of the level of technical fitness of young basketball players have shown that their individual indicators have a low rate of growth from year to year. So, the percentage of growth in 17 years old players in the movement in a defensive stance in relation to 11 years players was 21.50. The results of the study have shown that young basketball players, especially 14-15 years old players, have a small range of techniques. Young basketball players have a low level of skills of over-arm passing a ball with one hand, especially with the left one.

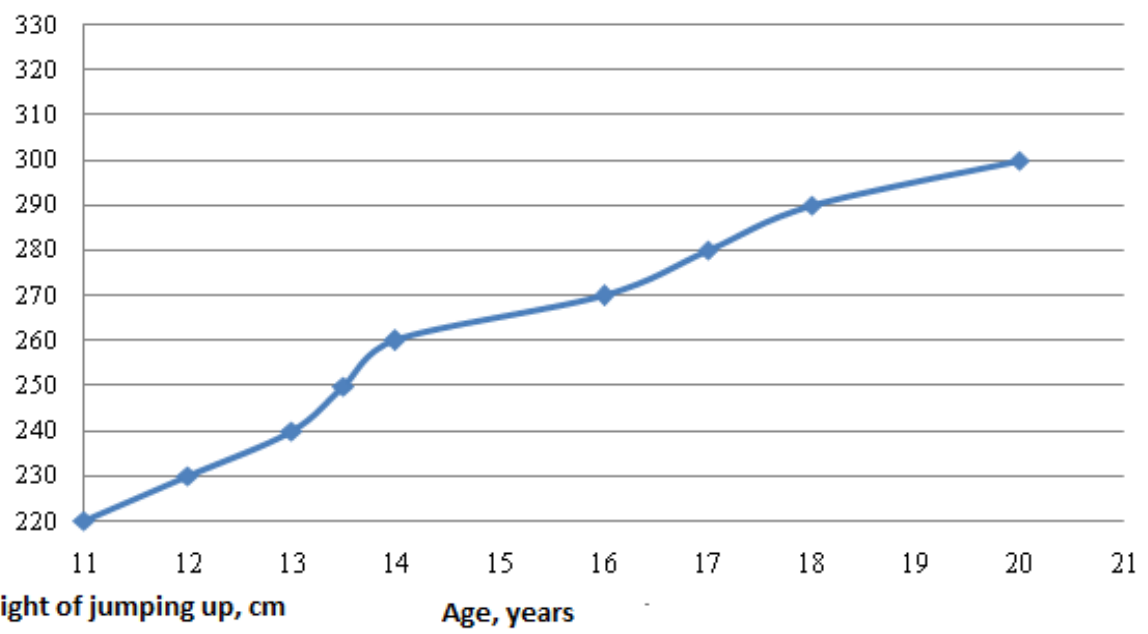

Fig. 3. Dynamics of indicators of absolute height of jumping up of young basketball players

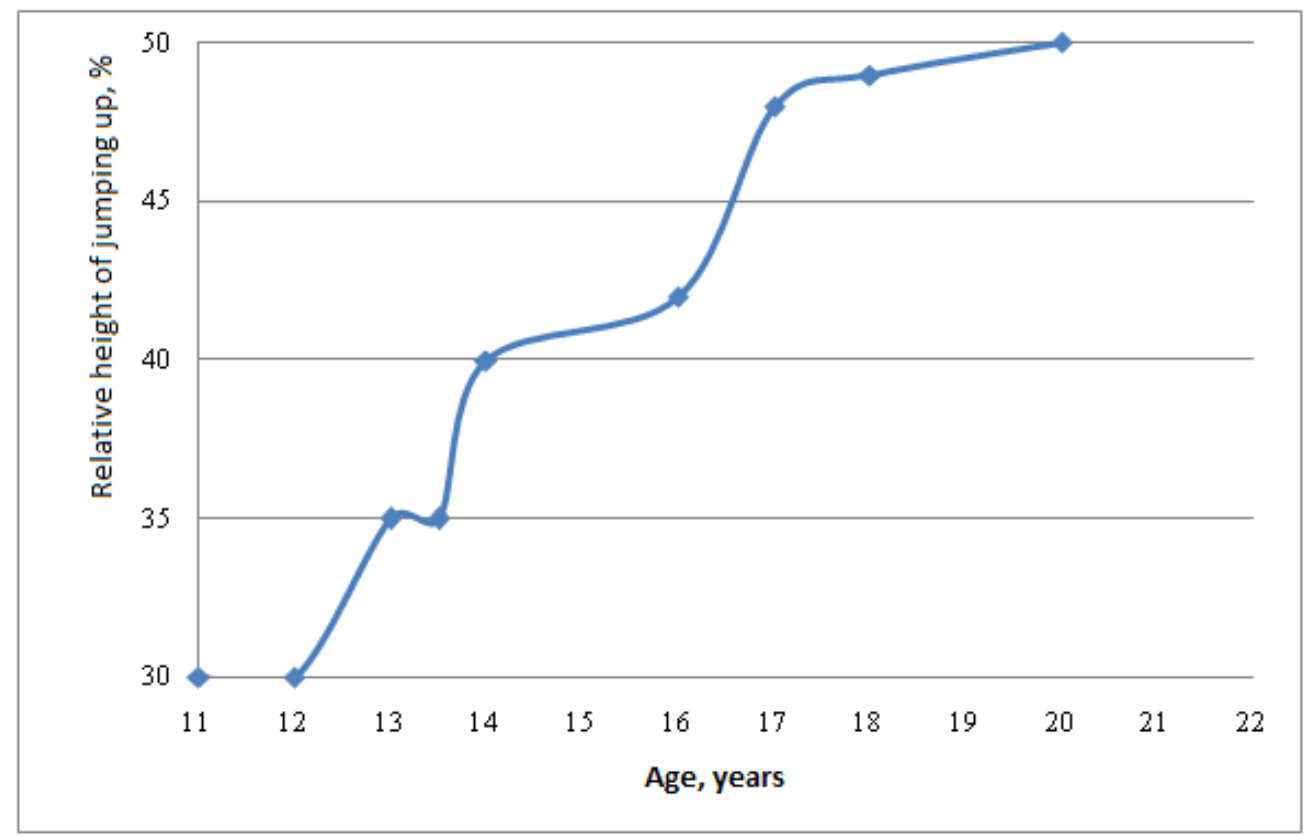

Fig. 4. Dynamics of indicators of relative height of jumping up of young basketball players 


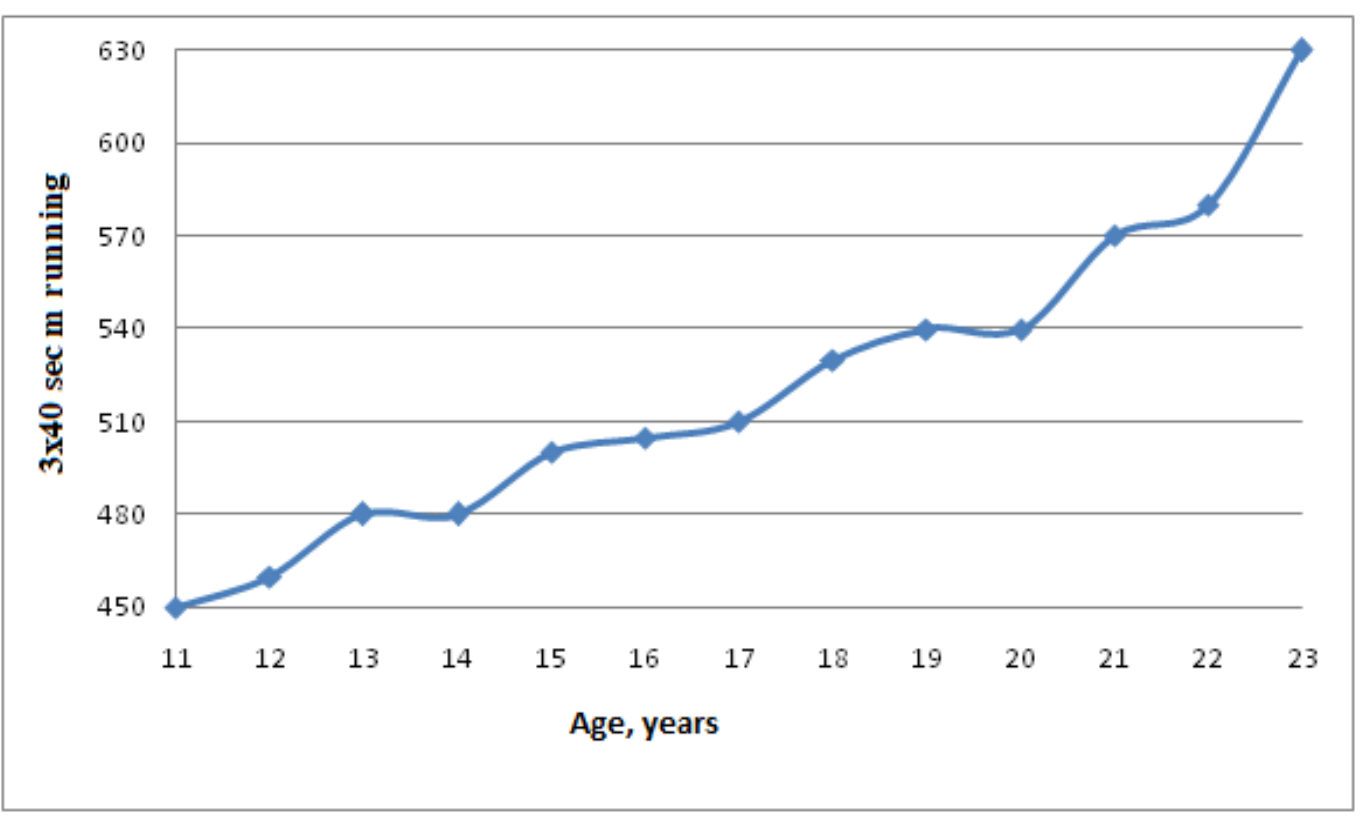

Fig. 5. Dynamics of indicators of speed endurance of young basketball players

Concerning other indicators of technical fitness, the rate of growth is higher from year to year, but in general, young basketball players have low rates in tests that characterize the development level of techniques. It has been found that the percentage of foul throws performed by the young basketball players was: 11 years old players - 24,70; 12 years old players - 31,90; 13 years old players $-35,10 ; 14$ years old players $-50,30 ; 15$ years old players $-53,60 ; 16$ years old players -58.00 and 17 years old players $-67.00 \%$.

The analysis of the obtained results allows us to conclude that the selection work should be raised to a higher level. This conclusion confirms the available data in the literature (Cañadas et al., 2015; Khlifa et al., 2013; Mulazimoglu et al., 2017).

The study of the growth rates of young basketball players has shown that they are generally at a level that is lower than recommended by the programs (Savoy et al., 1997; Tsamourtzis et al., 2002). The results of the growth indicators in different age categories are explained by the fact that basketball players of high qualification participated in the surveys in groups of 18-19 years old players, while in other age categories indicators of young basketball players of mass grades were used.

A very important indicator is the height of standing on tiptoe with a hand stretched up (Csataljay et al., 2009; Koryahin et al., 2015). Their importance lies in the fact that they allow taking into account such a factor as the length of the hands and feet.

It has been established that, in comparison with other sports (especially volleyball players) (Savoy et al., 1997), basketball players of high qualification have low indicators of the relative height of the jump. Naturally, this also affects the absolute height of the jump, which in basketball players gets stabilized till the age of 18 years old (Hoare et al., 2000).

On the basis of the obtained results, special attention should be paid to the level of development of high-speed endurance. Consequently, at the age of 11-17 years old, it is necessary to look for opportunities for increasing the efficiency of the training process concerning the development of high-speed endurance. This is consistent with the available literature data (Ben Abdelkrim et al., 2010; Castagna et al., 2007; Csataljay et al., 2009; Savoy et al., 1997).

In general, the study of technical and physical fitness of young basketball players of Ukraine at the age of 11-19 years old has shown that they are generally at a lower level, than recommended by the existing programs (Koryahin et al., 2016). The best indicators can be belong, first of all, to the indicators of 18-19 years old players (Erculj et al., 2009).

According to the range of techniques used, it has been found that at the age of 17-19, the basketball players should master the maximum number of techniques of the game (Cañadas et al., 2015; Tsamourtzis et al., 2002). In this regard, it is necessary, in our view, to review the approaches to assessing the effectiveness of the work of trainers. One of the main criteria for assessing the effectiveness of their work should be the degree of compliance of young basketball 
players with model characteristics (Dale et al., 1996; Hoare et al., 2000), among which the leading place belongs to a wide range of technical fitness. The tests used to assess the level of technical as well as physical fitness should cover a wider range.

\section{Conclusion}

1. The insufficient development of all physical qualities increases the duration of the formation of special skills during mastering the techniques of the kind of sports and reduces the effectiveness of their use in competitive games.

2. Rather low indicators that characterize the growth of sportsmen indicate a low level of selection work. The level of development of high-speed endurance in young basketball players at the age of 11-17 years old indicates that it should, taking into account the tasks of technical training, look for opportunities to increase the effectiveness of the training process in terms of development of high-speed endurance.

3. The low level of technical fitness and weak growth rates from year to year reduce the ability of young basketball players to master hidden passes and a number of other techniques.

4. The lack of due attention to the age-old peculiarities of young basketball players and to the distribution of the amount of time for training, and especially technical training, is aggravated by the fact that teams of 12-14 years old basketball players are formed in the Youth Sports School, due to which early specialization begins, which is focused on the formation of players for a certain role and training them to participate in the competition. There is no consistency or full scope in the development of the techniques, skills or formation of originality in it.

5. Along with the introduction of normative indicators in full concerning physical and technical fitness, rational distribution of time for all types of training by years of training and improvement of the competition system will allow to significantly increase the level of work with young basketball players in terms of their long-term training.

\section{References}

Ben Abdelkrim et al., 2010 - Ben Abdelkrim, N., Castagna, C., El Fazaa, S., El Ati, J. (2010). The effect of players' standard and tactical strategy on game demands in men's basketball Jour. Strength Cond Res. 24: 2652-2662.

Cañadas et al., 2015 - Cañadas, M., Ibáñez, J.S., Leite, N. (2015). A novice coach's planning of the technical and tactical content of youth basketball training: A case study. Inter. Jour. of Performance Analysis in Sport. 15(2): 572-587. DOI: https://doi.org/10.1080/24748668.2015. 11868815

Castagna et al., 2007 - Castagna, C., Manzi, V., D’Ottavio, S., Annino, G., Padua, E., Bishop, D. (2007). Relation between maximal aerobic power and the ability to repeat sprints in young basketball players. The Jour. of Strength \& Conditioning Research. 21: 1172-1176.

Csataljay et al., 2009 - Csataljay, G., O'Donoghue, P., Hughes, M., Dancs, H. (2009). Performance indicators that distinguish winning and losing teams in basketball. Inter. Jour. of Performance Analysis of Sport. 9: 60-66.

Dale et al., 1996 - Dale, G., Wrisberg, C. (1996). The use of a performance profile technique in a team setting: Getting the athletes and coach on the 'same page'. Sport Psychologist. 10: 261-277. DOI: https://doi.org/: 10.1123/tsp.10.3.261

Doroshenko et al., 2019 - Doroshenko, E., Sushko, R., Koryahin, V., Pityn, M., Tkalich, I., Blavt, $O$. (2019). The competitive activity structure of highly skilled. Basketball players on the basis of factor analysis methods. Human Movement. 20(4): 33-40.

Erculj et al., 2009 - Erculj, F., Supej, M. (2009). Impact of fatigue on the position of the release arm and shoulder girdle over a longer shooting distance for an elite basketball player. Jour. of Strength Conditioning Research. 23(3): 1029-1036.

Hoare et al., 2000 - Hoare, D.G. (2000). Predicting success in junior elite basketball players the contribution of anthropometic and physiological attributes. Jour. Sci Med Sport. 3(4): 391-405.

Khlifa et al., 2013 - Khlifa, R., Aouadi, R., Shephard, R., Chelly, M.S., Hermassi, S., Gabbett, T.J. (2013). Effects of a shoot training programme with a reduced hoop diameter rim on free-throw performance and kinematics in young basketball players. Jour. of Sports Sciences. 31(5): 497-504. DOI: https://doi.org/: 10.1080/02640414.2012.736634 


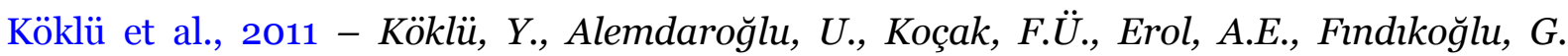
(2011). Comparison of Chosen Physical Fitness Characteristics of Turkish Professional Basketball Players by Division and Playing Position. Jour. of Human Kinetics. 30: 99-106. DOI: https://doi.org/10.2478/v10078-011-0077-y

Koryahin et al., 2015 - Koryahin, V., Blavt, O. (2011). Technological Conversion of a System for Test Control of the Leaping Ability. European Jour. of Physical Education and Sport. 1(7): 46-52.

Koryahin et al., 2015 - Koryahin, V., Blavt, O. (2015). Technological Conversion of a System for Test Control of the Leaping Ability. European Journal of Physical Education and Sport. 1(7): 46-52.

Koryahin et al., 2016 - Koryahin, V., Blavt, O., Grebinca, G. (2015). Optimization of the technical training system. Jour. of Physical Education and Sport. 16(2): 1029-1030. DOI: https://doi.org/:10.7752/jpes.2016.s2163

Kuczek et al., 2013. - Kuczek, P. (2013). On the possibility of applying achievement goal theory in competitive sports. Hum Mov. 14(2): 129-137. DOI: https://doi.org/10.2478/humo-2013-0015.

Mancha-Triguero et al., 2019 - Mancha-Triguero, D., García-Rubio, J., Ibáñez, S.J. (2019). Batería de test de campo para evaluar la condición física de jugadores de baloncesto: SBAFIT. E-Bm. J. Sci. Sport. 15: 107-126.

Mulazimoglu et al., 2017 - Mulazimoglu, O., Yanar, S., Evcil, A.T., Duvan, A. (2017). Examining the effect of fatigue on shooting accuracy in young basketball players. The Anthropologist. 27(1-3): 77-80. DOI: https://doi.org/010.1080/09720073.2017.1311671

Savoy et al., 1997 - Savoy, C. (1997). Two individualized mental training programs for a team sport. Inter. Jour. of Sport Psychology. 28: 259-270.

Tsamourtzis et al., 2002 - Tsamourtzis, E., Saloninkidis, K., Taxildaris, K., Mawromatis, G. (2002). Technisch-taktische Merkmale von Siegern und Verlierern bei Herrenbasketballmannschaften [Technical-tactical characteristics of winners and losers in men's basketball teams]. Leistungssport. 1: 54-58. [in German]

Villani et al., 2017 - Villani, D., Caputo, M., Balzarotti, S., Riva, G. (2017). Enhancing selfefficacy through a blended training: A pilot study with basketball players. International Jour. of Sport and Exercise Psychology. 15(2): 160-175. DOI: https://doi.org/10.1080/1612197X.2015.1079921 